\title{
QUEEN'S
UNIVERSITY
BELFAST
}

\section{Evidence for sex differences in the determinants of homocysteine concentrations}

Stanislawska-Sachadyn, A., Woodside, J., Brown, K. S., Young, I., Murray, L., McNulty, H., Strain, J. J., Boreham, C. A., Scott, J. M., Whitehead, A. S., \& Mitchell, L. E. (2008). Evidence for sex differences in the determinants of homocysteine concentrations. Molecular Genetics and Metabolism, 93(4), 355-362. https://doi.org/10.1016/j.ymgme.2007.11.004

Published in:

Molecular Genetics and Metabolism

Queen's University Belfast - Research Portal:

Link to publication record in Queen's University Belfast Research Portal

\section{General rights}

Copyright for the publications made accessible via the Queen's University Belfast Research Portal is retained by the author(s) and / or other copyright owners and it is a condition of accessing these publications that users recognise and abide by the legal requirements associated with these rights.

Take down policy

The Research Portal is Queen's institutional repository that provides access to Queen's research output. Every effort has been made to ensure that content in the Research Portal does not infringe any person's rights, or applicable UK laws. If you discover content in the Research Portal that you believe breaches copyright or violates any law, please contact openaccess@qub.ac.uk. 


\title{
Evidence for sex differences in the determinants of homocysteine concentrations
}

\author{
Anna Stanisławska-Sachadyn ${ }^{a}$, Jayne V. Woodside ${ }^{b}$, Karen S. Brown ${ }^{a}$, Ian S. Young ${ }^{b}$, \\ Liam Murray ${ }^{b}$, Helene McNulty ${ }^{c}$, J.J. Strain ${ }^{c}$, Colin A. Boreham ${ }^{d}$, John M. Scott ${ }^{e}$, \\ Alexander S. Whitehead ${ }^{\mathrm{a}, *}$, Laura E. Mitchell ${ }^{\mathrm{f}}$ \\ ${ }^{a}$ Department of Pharmacology and Center for Pharmacogenetics, University of Pennsylvania School of Medicine, \\ 153 Johnson Pavilion, 3620 Hamilton Walk, Philadelphia, PA 19104-6084, USA \\ ${ }^{\mathrm{b}}$ Cardiovascular Research Centre, Queen's University Belfast, Belfast, Northern Ireland, UK \\ ${ }^{\mathrm{c}}$ Northern Ireland Centre for Food and Health, University of Ulster, Coleraine, Northern Ireland, UK \\ ${ }^{\mathrm{d}}$ Institute for Sport and Health, University College, Dublin, Ireland \\ ${ }^{\mathrm{e}}$ Department of Clinical Medicine, Trinity College, Dublin, Ireland \\ ${ }^{\mathrm{f}}$ The Texas A\&M University System Health Science Center, Institute of Biosciences and Technology, Houston, TX 77030, USA
}

Received 5 September 2007; received in revised form 7 November 2007; accepted 7 November 2007

Available online 3 January 2008

\begin{abstract}
A high homocysteine phenotype, often accompanied by low folate, is associated with several pathologies including cardiovascular disease and birth defects. This phenotype appears to be influenced by both genetic and environmental factors, which may act in a sex-dependent manner. The present analyses were undertaken to identify the determinants of homocysteine concentrations in young men and women, and are based on data from a cohort of young, reproductive age (20-26 years old) individuals in Northern Ireland. Multivariate modeling indicated that homocysteine concentrations are associated with red blood cell (RBC) folate, vitamin $\mathrm{B}_{12}, M T H F R$ $677 \mathrm{C}>\mathrm{T}$ genotype and smoking status in both males and females. However, the inter-relationships between these variables appear to differ between the sexes. Specifically, homocysteine levels in males were significantly associated with interactions between $M T H F R$ $677 \mathrm{C}>\mathrm{T}$ genotype and both $\mathrm{RBC}$ folate and smoking status. In contrast, homocysteine levels in females were significantly associated with interactions between smoking status and RBC folate. These results suggest that the characteristics of individuals who are at the highest risk for a high homocysteine phenotype differ for males and females. Among males, those with the MTHFR 677TT genotype appear to be at the highest risk and to be the most vulnerable to factors (e.g. smoking, low RBC folate) that are associated with homocysteine raising effects. Among females, smokers (regardless of MTHFR genotype) appear to be at the highest risk, and to be the most vulnerable to a single factor (i.e. RBC folate) that is associated with homocysteine raising effects.
\end{abstract}

(C) 2007 Elsevier Inc. All rights reserved.

Keywords: Sex; Smoking; Folate; Homocysteine; Hyperhomocysteinaemia

\section{Introduction}

A high homocysteine phenotype accompanied by low folate is associated with increased risk of several major human pathologies including cardiovascular disease [1,2],

\footnotetext{
* Corresponding author. Fax: +1 2155739135.

E-mail address: aswhitehead@pharm.med.upenn.edu (A.S. Whitehead).
}

birth defects such as spina bifida [3] and cleft palate [4], and other complications of pregnancy including spontaneous abortion, pre-eclampsia, prematurity and low birth weight [5]. Folate is required for nucleic acid biosynthesis and the methylation of lipids, hormones, DNA and proteins, while homocysteine is a key intermediate in the methylation cycle [5] and may itself be teratogenic [6,7]. As periconceptional folic acid supplementation is known to reduce the risk of spina bifida $[3,8,9]$, the reciprocal quan- 
titative relationship between folate and homocysteine [10] is of particular importance to women of childbearing age.

Recognition that mild hyperhomocysteinemia is a cardiovascular risk factor/marker [1,2] has prompted considerable research into understanding the biochemical, environmental and genetic influences that have an impact on homocysteine concentrations. The variables known to be significantly associated with homocysteine levels include: vitamin status, in particular folate, riboflavin and vitamin $\mathrm{B}_{12}$; age; sex; lifestyle, in particular smoking status; prescription drugs; renal function; and genetics, in particular the well-established influence of the $677 \mathrm{C}>\mathrm{T}$ polymorphism in the 5,10-methylenetetrahydrofolate reductase $(M T H F R)$ gene [11].

It has previously been shown that the median plasma total homocysteine concentration is higher among men than women [12]. In addition, many studies have investigated the relationship between smoking and homocysteine levels. Although these studies have not been entirely consistent in their findings, the majority has reported a positive correlation between smoking and homocysteine levels $[13,14]$. In the Norwegian "Hordaland" study of almost 25,000 middle aged (40-42 years) and older (65-67 years) adults plasma total homocysteine concentration was positively correlated with the number of cigarettes smoked per day and the homocysteine raising effect of smoking appeared to be somewhat stronger in women and in the younger age group [12].

The MTHFR 677TT genotype confers a significant risk of hyperhomocysteinemia that is most pronounced in individuals with low folate $[15,16]$ or low riboflavin [17] status. Interestingly, the MTHFR $677 \mathrm{C}>\mathrm{T}$ polymorphism appears to have a sex-specific effect on homocysteine [18]. Men who are MTHFR 677TT homozygotes appear to be at higher risk of hyperhomocysteinemia than women with this genotype [19]. Furthermore, the impact of the MTHFR 677TT genotype on homocysteine may be largely restricted to male smokers and may have little influence on females regardless of smoking behavior [20].

Given the association between homocysteinemia and several disease phenotypes, identification of the factors that influence variation in homocysteine levels is of considerable public health interest. In this report we describe our investigation of the determinants of homocysteine concentrations in a cohort of young, reproductive age adults.

\section{Population and methods}

\section{Study population}

The Young Hearts Project ( $\mathrm{YH}$ ) is an ongoing longitudinal study designed to monitor cardiovascular disease risk factors in children and young adults living in Northern Ireland [21]. Briefly, a sample of 12 year old $(n=509)$ and 15 year old $(n=506)$ boys and girls were enrolled from postprimary schools in Northern Ireland between 1989 and 1990 (YH1). Between October 1997 and October 1999, all
YH subjects were invited to participate in a hospital-based screening evaluation (YH3) [22]. The participation rate for YH3, which was conducted when the subjects were between 20 and 26 years of age, was $48.2 \%(n=489)$. Compared to non-respondents, YH3 subjects tended to be from families with higher socioeconomic status and to have lower body mass indices at the baseline (YH1) exam. In addition, male $\mathrm{YH} 3$ subjects were leaner and reported lower saturated fat intake at baseline relative to the male non-participants [23]. Ethical approval for each phase of the study was granted by the Research Ethics Committee of Queen's University Belfast. The current paper is based on self-reported data on smoking status, use of alcohol and multivitamin supplements, and fasting blood samples collected as part of $\mathrm{YH} 3$.

\section{Laboratory methods}

Homocysteine was measured by an established high performance liquid chromatography method [24]. Serum folate and vitamin $\mathrm{B}_{12}$ were determined by time-resolved immunofluorescence on an AutoDelfia analyzer (Wallac, UK). Red blood cell (RBC) folate concentrations were determined by a microbiological assay [25], and are expressed as nanomoles per liter of packed RBCs. Creatinine was measured using an enzyme-based assay on an Ektachem analyzer (Johnson \& Johnson). DNA was extracted [26] and the MTHFR $677 \mathrm{C}>\mathrm{T}$ genotype $[19,20]$ was determined as previously described.

\section{Statistical methods}

Descriptive analyses of the study variables were conducted using data from all study subjects, and within the subset of data provided by study subjects who had complete information for all variables of interest. These analyses were performed separately in data from male and female YH3 participants.

Using data from all study subjects, the Wilcoxon rank sum test and the chi-square test were used, respectively, to evaluate differences in continuous and categorical variables between males and females. As the distribution of $\mathrm{RBC}$ folate, vitamin $\mathrm{B}_{12}$ and homocysteine are positively skewed, these analyses were conducted using log transformed values. All tests were two-tailed and $P$-values of $<0.05$ were considered to be statistically significant.

Simple and multiple linear regression analyses were conducted separately in data from males and females, using log transformed homocysteine values as the main outcome measure. These analyses were restricted to the subset of YH3 study participants who had complete data for all of the variables that were included in the regression analyses. Simple linear regression models were fitted to the data and the coefficient of determination $\left(R^{2}\right)$ estimated from these models was used to assess the proportion of variation in homocysteine concentrations that was explained by each predictor variable. In addition, 
the variable coefficients were used to estimate the direction and magnitude of the association between the variable and homocysteine levels. The significance of the association between each variable and homocysteine levels was assessed using the $t$-statistic.

Multiple regression models, including predictor variables and two-way interaction action terms, were also fitted to the data. In all multivariate models, the MTHFR CC and $\mathrm{CT}$ genotypes were combined to form a single category that was compared to the TT genotype. Adjusted $R^{2}$ values were used to compare nested models [27] and the difference in the adjusted $R^{2}$ between models was used to estimate the proportion of variation in homocysteine concentrations explained by the addition of a single predictor variable or interaction term to a model. An increase in the adjusted $R^{2}$ of $1 \%$ or more was considered of interest. The significance of individual predictor variables within a model was assessed using the $t$-statistic. Variables with $P$-value $<0.05$ were considered to be significantly related to homocysteine concentration, given all other variables in the model. All statistical analyses were carried out using SAS version 8.02 or 9.1 .

\section{Results}

Characteristics of all YH3 study subjects and the subset of subjects with complete data for the variables of interest in this study are summarized, separately by sex, in Table 1 . In the full cohort, median $\mathrm{RBC}$ folate, vitamin $\mathrm{B}_{12}$ and creatinine concentrations were significantly lower in women than in men $(P<0.01)$. Median homocysteine levels were also lower in women than in men, but this difference was not statistically significant. There were also differences between the sexes in lifestyle variables that are known to have an impact on homocysteine. Specifically, males were more likely to report consuming alcohol than females $(P=0.05)$, and among those who reported the use of alcohol, intake was higher in males than females $(P<0.01)$. Although the proportion of males and females who reported that they smoked cigarettes was similar, male smokers reported significantly higher numbers of cigarettes smoked per day than did female smokers $(P=0.04)$. In addition, males were less likely than females to report the use of a multivitamin supplement, although this difference was not statistically significant. The characteristics of the subset of subjects with complete data for all of the study variables did not differ markedly from those of the full study cohort.

Given the observed differences in the biochemical and lifestyle variables between the sexes, all subsequent analyses were performed separately for males and females. In both males and females, RBC folate was significantly inversely related to, and explained the highest proportion of the variability in, homocysteine level $\left(\mathrm{R}_{\text {male }}^{2}=0.21\right.$, $\mathbf{R}_{\text {female }}^{2}=0.26$, Table 2 ). Vitamin $B_{12}$ was also significantly and inversely related to, and explained the second highest proportion of the variation in, homocystiene concentration in both sexes $\left(\mathrm{R}_{\text {male }}^{2}=0.17, \mathrm{R}_{\text {female }}^{2}=0.14\right)$. Use of multivitamin supplements and genotype for the MTHFR $677 \mathrm{C}>\mathrm{T}$ variant were also significantly associated with homocysteine in both sexes. These two variables each explained 3$5 \%$ of the variation in homocysteine concentration (Table 2). Smoking status accounted for approximately $7 \%$ of the variation in homocysteine concentration in females, but was not significantly associated with homocysteine concentrations in males. Creatinine and use of alcohol were not significantly associated with homocysteine levels in either sex, and accounted for $2 \%$ or less of its variation.

As a first step in the multivariate analyses, a model including the three variables that were significantly associated with homocysteine concentration in both sexes in the simple regression models (i.e. $\mathrm{RBC}$ folate, vitamin $\mathrm{B}_{12}$ and MTHFR $677 \mathrm{C}>\mathrm{T}$ genotype) was fitted to the data (Model $1)$. For both males and females, each of the individual predictor variables in Model 1 remained significantly associated with homocysteine $(P<0.05)$, and the model explained approximately $30 \%$ of the variation in homocysteine levels (Table 3). Models including two-way interaction terms between the variables in Model 1 were then fitted to the data (Table 3, Models 1a-1c). Among females, the inclusion of any one of these interaction terms did not markedly increase the proportion of variation in homocysteine concentration explained by the model (i.e. change in adjusted $\left.R^{2}<0.01\right)$ and none of the interaction terms were statistically significant. In contrast, among males, interaction terms between $\mathrm{RBC}$ folate and vitamin $\mathrm{B}_{12}$ and between RBC folate and MTHFR genotype were both significantly related to homocysteine level $(P=0.02$ and $P<0.01$, respectively), and increased the proportion of variation explained by the model by approximately $2 \%$ and $8 \%$, respectively. However, the model that included both interaction terms did not explain an increased proportion of the variation in homocysteine concentration, relative to the model that included only the interaction term for RBC folate and MTHFR genotype, and the interaction between RBC folate and MTHFR genotype was statistically significant $(P<0.01)$, whereas the interaction between $\mathrm{RBC}$ folate and vitamin $\mathrm{B}_{12}$ was not $(P=0.14)$.

To determine whether the lifestyle variables are associated with homocysteine concentrations independent of the effects of $\mathrm{RBC}$ folate, vitamin $\mathrm{B}_{12}$ and MTHFR genotype a second series of multiple regression models were fitted to the data. Given prior results indicating that in males, but not females, homocysteine is associated with an interaction between RBC folate and MTHFR genotype, the base model used for these analyses differed for males and females. In males, a model including RBC folate, vitamin $\mathrm{B}_{12}, M T H F R$ genotype and an interaction term between RBC folate and MTHFR genotype was fitted to the data (Table 3, Model 2M), and compared to models that included all of these terms plus a term for one of the lifestyle variables (Table 3, Models 2a-c). In the context of this model, smoking status was significantly related to homocysteine concentration $(P=0.03)$; its addition 
Table 1

Characteristics of participants in the Young Hearts 3 study

\begin{tabular}{|c|c|c|c|c|}
\hline \multirow[t]{2}{*}{ Variable } & \multicolumn{2}{|l|}{ Males } & \multicolumn{2}{|l|}{ Females } \\
\hline & Full dataset & Subset $^{\mathrm{a}}$ & Full dataset & Subset $^{\mathrm{a}}$ \\
\hline \multicolumn{5}{|l|}{ Biochemical variables } \\
\hline \multicolumn{5}{|l|}{ Homocysteine $(\mu \mathrm{mol} / \mathrm{l})$} \\
\hline$N$ & 229 & 160 & 191 & 149 \\
\hline Mean & 10.2 & 10.1 & 9.8 & 9.6 \\
\hline Median (25th-75th percentile) & $9.2(7.6-11.0)$ & $9.2(7.6-10.8)$ & $8.6(7.3-10.9)$ & $8.5(7.2-10.6)$ \\
\hline \multicolumn{5}{|l|}{ Red blood cell folate (nmol/l RBCs) } \\
\hline$N$ & 198 & 160 & 182 & 149 \\
\hline Mean & 747.1 & 734.1 & 626.4 & 629.8 \\
\hline Median (25th-75th percentile) & $702.4(541.1-888.7)$ & $688.7(530.1-880.8)$ & $562.9(428.7-752.0)$ & $560.4(428.2-746.3)$ \\
\hline \multicolumn{5}{|l|}{ Serum vitamin $B_{12}(\mathrm{pmol} / \mathrm{l})$} \\
\hline$N$ & 200 & 160 & 166 & 149 \\
\hline Mean & 304.6 & 307.8 & 244.0 & 241.4 \\
\hline Median (25th-75th percentile) & $293.5(211.5-370.5)$ & $295.5(213.5-370.5)$ & $242.0(173.0-300.0)$ & $238.0(171.0-297.0)$ \\
\hline \multicolumn{5}{|l|}{ Creatinine $(\mu \mathrm{mol} / \mathrm{l})$} \\
\hline$N$ & 228 & 160 & 189 & 149 \\
\hline Mean & 73.5 & 74.4 & 54.9 & 54.8 \\
\hline Median (25th-75th percentile) & $73.0(67.0-81.0)$ & $73.5(67.5-81.5)$ & $55.0(47.0-63.0)$ & $55.0(48.0-63.0)$ \\
\hline \multicolumn{5}{|l|}{ Lifestyle Variables } \\
\hline \multicolumn{5}{|l|}{ Current use of cigarettes $(N, \%)$} \\
\hline Yes & $87(37.5)$ & $53(33.1)$ & $77(38.9)$ & $61(40.9)$ \\
\hline No & $145(62.5)$ & $107(66.9)$ & $121(61.1)$ & $88(59.1)$ \\
\hline \multicolumn{5}{|l|}{ Cigarettes (per day) ${ }^{\mathrm{b}}$} \\
\hline$N$ & 87 & 53 & 77 & 61 \\
\hline Mean & 12.4 & 13.5 & 10.0 & 10.0 \\
\hline Median (25th-75th percentile) & $10(7-20)$ & $12(10-20)$ & $10(5-15)$ & $10(5-11)$ \\
\hline \multicolumn{5}{|l|}{ Current use of alcohol $(N, \%)$} \\
\hline Yes & $199(81.2)$ & $137(85.6)$ & $154(77.8)$ & $116(77.9)$ \\
\hline No & $46(18.8)$ & $23(14.4)$ & $44(22.2)$ & $33(22.1)$ \\
\hline \multicolumn{5}{|l|}{ Alcohol $(\mathrm{g} / \text { day })^{\mathrm{c}}$} \\
\hline$N$ & 199 & 137 & 154 & 116 \\
\hline Mean & 53.4 & 53.8 & 19.8 & 19.4 \\
\hline Median (25th-75th percentile) & $43.0(27.0-69.0)$ & $43.0(27.0-66.0)$ & $16.0(8.0-25.0)$ & $16.5(9.0-24.5)$ \\
\hline \multicolumn{5}{|c|}{ Current use of multivitamin supplements $(N, \%)$} \\
\hline Yes & $46(19.7)$ & $33(20.6)$ & $51(25.8)$ & $44(29.5)$ \\
\hline No & $188(80.3)$ & $127(79.4)$ & $147(74.2)$ & $105(70.5)$ \\
\hline \multicolumn{5}{|l|}{ Genotypes } \\
\hline \multicolumn{5}{|l|}{ MTHFR $677 \mathrm{C}>\mathrm{T}(N, \%)$} \\
\hline $\mathrm{CC}$ & $102(45.3)$ & $73(45.6)$ & $81(41.8)$ & $63(42.3)$ \\
\hline $\mathrm{CT}$ & $99(44.0)$ & $70(43.8)$ & $80(41.2)$ & $63(42.3)$ \\
\hline TT & $24(10.7)$ & $17(10.6)$ & $33(17.0)$ & $23(15.4)$ \\
\hline
\end{tabular}

a Subset limited to data from study subjects with complete information for all of the study variables.

${ }^{\mathrm{b}}$ Cigarettes smoked per day among smokers.

c Alcohol consumed per day among alcohol users.

increased by $1.5 \%$ the proportion of variation in homocysteine explained (Model 2a). In contrast, neither alcohol use $(P=0.56)$ nor multivitamin use $(P=0.52)$ was significantly related to homocysteine concentration, and the addition of either variable did not appreciably influence the proportion of homocysteine variation explained by the model (Table 3, Models $2 \mathrm{~b}$ and $2 \mathrm{c}$, respectively). Among females, a model including only $\mathrm{RBC}$ folate, vitamin $\mathrm{B}_{12}$, and MTHFR genotype was fitted to the data
(Table 3, Model 2f). In the context of this model, the association between smoking status and homocysteine concentration was of borderline significance $(P=0.07)$, and the addition of this variable increased the proportion of variation in homocysteine explained by the model by only $1.0 \%$ (Model 2a). In contrast, neither alcohol use $(P=0.17)$ nor multivitamin use $(P=0.66)$ was related to homocysteine concentration, and the addition of either variable did not appreciably influence the proportion of homocysteine var- 
Table 2

Proportion of the variation $\left(R^{2}\right)$ in homocysteine concentration explained by selected biochemical and behavioral factors in Young Hearts 3 study participants

\begin{tabular}{|c|c|c|c|c|}
\hline \multirow[t]{2}{*}{ Predictor variables } & \multicolumn{2}{|l|}{ Males } & \multicolumn{2}{|l|}{ Females } \\
\hline & $R^{2}(P \text {-value })^{\mathrm{a}}$ & Variable coefficient $(\mathrm{SE})^{\mathrm{b}}$ & $R^{2}(P \text {-value })^{\mathrm{a}}$ & Variable coefficient $(\mathrm{SE})^{\mathrm{b}}$ \\
\hline Red blood cell folate (nmol/1) & $0.21(<0.01)$ & $-0.0002(0.00004)$ & $0.26(<0.01)$ & $-0.0002(0.00003)$ \\
\hline Serum vitamin $\mathrm{B}_{12}(\mathrm{pmol} / \mathrm{l})$ & $0.17(<0.01)$ & $-0.0005(0.00008)$ & $0.14(<0.01)$ & $-0.0006(0.0001)$ \\
\hline Creatinine $(\mu \mathrm{mol} / \mathrm{l})$ & $0.004(0.43)$ & $0.0007(0.0009)$ & $0.02(0.07)$ & $0.0019(0.0011)$ \\
\hline Current use of cigarettes (yes/no) & $0.005(0.39)$ & $-0.0211(0.0246)$ & $0.07(<0.01)$ & $0.0850(0.0250)$ \\
\hline Current use of alcohol (yes/no) & $0.001(0.26)$ & $0.0374(0.0330)$ & $0.02(0.10)$ & $0.0545(0.0305)$ \\
\hline Current use of multivitamin supplements (yes/no) & $0.03(0.03)$ & $0.0619(0.0283)$ & $0.04(0.01)$ & $0.0706(0.0274)$ \\
\hline MTHFR $677 \mathrm{C}>\mathrm{T}$ & $0.05(0.83,0.01)^{\mathrm{c}}$ & & $0.05(0.28,0.01)$ & \\
\hline $\mathrm{CT}$ & & $-0.0053(0.0240)$ & & $0.0296(0.0272)$ \\
\hline TT & & $0.1046(0.0387)$ & & $0.1042(0.0372)$ \\
\hline
\end{tabular}

a $P$-value for test of hypothesis of no linear association between predictor variable and homocysteine concentration.

${ }^{b}$ Estimated regression coefficients and standard errors, variable coefficients estimate change in homocysteine concentration per unit change in the predictor variable.

${ }^{\mathrm{c}} P$-value from comparison of $M T H F R \mathrm{CC}$ and CT genotypes, $P$-value for comparison of $M T H F R \mathrm{CC}$ and TT genotypes.

Table 3

Summary of linear regression modeling of homocysteine concentrations in Young Hearts 3 study participants

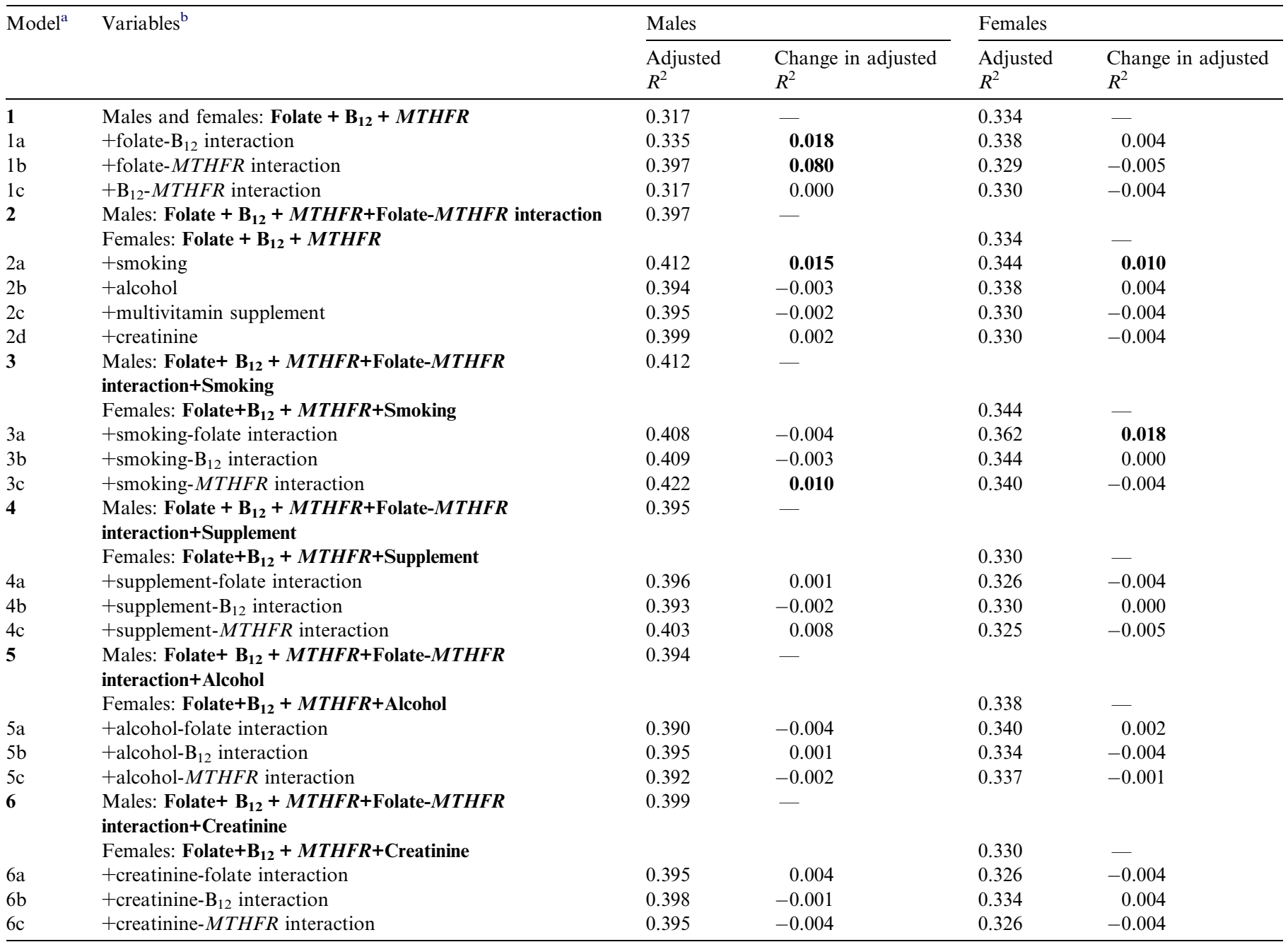

${ }^{\text {a }}$ Change in adjusted $R^{2}$ was assessed relative to the first model (indicated in bold) within each group. It is of note that the adjusted $R^{2}$ need not increase when a variable is added to a model and that the change in the adjusted $R^{2}$ value upon addition of a variable to the model can be negative, indicating that the additional variable does not contribute any explanatory power to the model.

${ }^{\mathrm{b}}$ In all analyses the MTHFR CC and CT genotypes were combined and compared to the TT genotype. 
iation explained by the model (Table 3, Models $2 \mathrm{~b}$ and $2 \mathrm{c}$, respectively).

To evaluate whether the associations between homocysteine and $\mathrm{RBC}$ folate, vitamin $\mathrm{B}_{12}$ and MTHFR genotype might be modified by lifestyle or other factors (i.e. kidney function indexed by creatinine), several additional multiple regression models were fitted to the data (Table 3, Models 3-6). These analyses indicated that, in males, an interaction between smoking and MTHFR genotype $(P=0.05)$ and, in females, an interaction between smoking and RBC folate $(P=0.02)$, were significantly related to homocysteine concentration and increased the proportion of variation in homocysteine that could be explained by the model by $1-$ $2 \%$ (Table 3, Model 3c in males and $3 \mathrm{a}$ in females). No other interaction term was significantly associated with homocysteine concentration, or with an appreciable increase in the proportion of variation in homocysteine explained by the model (Table 3, Models 4-6).

Hence, in these data, homocysteine concentration in males is best predicted by a model that includes $\mathrm{RBC}$ folate, vitamin $\mathrm{B}_{12}, M T H F R$ genotype, smoking status and interactions between MTHFR genotype and smoking status and MTHFR genotype and RBC folate. This model explains approximately $42 \%$ of the variation in homocysteine in males, and each of the terms in the models is statistically significant. Homocysteine concentrations in females are best predicted by a model that includes $\mathrm{RBC}$ folate, vitamin $\mathrm{B}_{12}, M T H F R$ genotype, smoking status and an interaction between RBC folate and smoking status. This model explains approximately $36 \%$ of the variation in homocysteine in females, and each of the terms in the model is statistically significant.

To illustrate the interactions suggested by the regression analyses, predicted homocysteine values were calculated from the best multiple regression model for males and females (Table 4). For example, to illustrate the predicted impact of the interaction between MTHFR and smoking, consider males with low folate and low $\mathrm{B}_{12}$ (Table 1, row 1). Among such individuals, homocysteine is predicted to be 33\% higher in non-smokers with the MTHFR TT genotype relative to those with the $\mathrm{CC}$ or $\mathrm{CT}$ genotypes, and $82 \%$ higher in smokers with the TT genotype relative those with the CC or CT genotype (Table 4, row 1). In general, for a given set of risk factors, the predicted homocysteine values for females are lower than the corresponding estimate for males (Table 4). The notable exception to this occurs in the subgroup of smokers with the MTHFR CC or CT genotype. In this subgroup, the predicted homocysteine levels for females are comparable to, or higher than those of males. Further, although predicted homocysteine levels in female smokers with the TT genotype are lower than those of their male counterparts (i.e. male smokers with the TT genotype), they are increased relative to female smokers with the CC or CT genotype. These findings suggest that, among young females, smoking eliminates the widely recognized sex difference in homocysteine concentration, and may expose females, regardless of the MTHFR $677 \mathrm{C}>\mathrm{T}$ genotype, to excess morbidity and mortality from homocysteine-related diseases.

\section{Discussion}

These analyses confirm previously reported associations between homocysteine and folate, vitamin $\mathrm{B}_{12}, M T H F R$ $677 \mathrm{C}>\mathrm{T}$ genotype and smoking status, and differences in homocysteine levels between males and females in a relatively unique cohort of young, reproductive age adults. In both males and females, folate and vitamin $\mathrm{B}_{12}$ explained the highest proportion of the variation in homocysteine concentration. In addition, for both males and females, MTHFR $677 \mathrm{C}>\mathrm{T}$ genotype and smoking status and interactions involving these variables were also significantly associated with homocysteine concentration, although these variables tended to explain a smaller proportion of the variation in homocysteine than folate and vitamin $B_{12}$.

Interestingly, although the same set of variables (i.e. $\mathrm{RBC}$ folate, vitamin $\mathrm{B}_{12}$, MTHFR $677 \mathrm{C}>\mathrm{T}$ genotype and smoking status) were identified in both males and females,

Table 4

Predicted homocysteine values for males and females ${ }^{\mathrm{a}}$

\begin{tabular}{|c|c|c|c|c|c|c|}
\hline \multirow[t]{2}{*}{ Sex } & \multirow[t]{2}{*}{$\mathrm{RBC}$ folate $^{\mathrm{b}}$} & \multirow[t]{2}{*}{ Vitamin $\mathrm{B}_{12}{ }^{\mathrm{b}}$} & \multicolumn{2}{|c|}{ Non-smoker } & \multicolumn{2}{|l|}{ Smoker } \\
\hline & & & $\mathrm{CC}$ or $\mathrm{CT}$ & TT & $\mathrm{CC}$ or $\mathrm{CT}$ & $\mathrm{TT}$ \\
\hline \multirow[t]{3}{*}{ Male } & 430 & 170 & 11.9 & 15.8 & 10.5 & 19.1 \\
\hline & 750 & 170 & 10.8 & 10.2 & 9.5 & 12.4 \\
\hline & 750 & 300 & 9.7 & 9.2 & 8.5 & 11.1 \\
\hline \multirow[t]{2}{*}{ Female } & 430 & 170 & 9.6 & 10.7 & 11.2 & 12.6 \\
\hline & 750 & 300 & 7.7 & 8.6 & 8.0 & 9.0 \\
\hline
\end{tabular}

${ }^{\mathrm{a}}$ Multiple regression model used to predict homocysteine concentrations in males: $\log$ hcy $=1.19491-(0.00013 \times$ folate $)-\left(0.00036 \times \mathrm{B}_{12}\right)+$ $(0.31561 \times$ MTHFR $)-(0.00045 \times$ folate $\times$ MTHFR $)-(0.05347 \times$ smoking $)+(0.13689 \times$ MTHFR $\times$ smoking $)$ Multiple regression model used to predict homocysteine concentrations in females: $\log$ hcy $=1.10731-(0.00014 \times$ folate $)-\left(0.00038 \times \mathrm{B}_{12}\right)+(0.05046 \times$ MTHFR $)+(0.13281 \times$ smoking $)-$ $(0.00015 \times$ smoking $\times$ folate $)$.

${ }^{b}$ Values correspond to sex-specific 25 th and 75 th percentiles in the subset of female study subjects used in the multiple regression model. 
the inter-relationships among these variables appeared to differ between the sexes. In males, the associations between homocysteine concentration and both $\mathrm{RBC}$ folate and smoking status were influenced by MTHFR genotype. In contrast, among females, the association between homocysteine concentration and both RBC folate and smoking appeared to be independent of MTHFR genotype, but there was evidence that homocysteine concentration was influenced by an interaction between RBC folate and smoking. These findings suggest that in young, reproductive age males, those with the MTHFR TT genotype are particularly vulnerable to factors that have a homocysteine raising effect, such as smoking and low folate status. The situation for young reproductive age females appears to be somewhat different. Specifically, young females who smoke appear to reduce or eliminate the protective effect of female gender on homocysteine levels, and to be particularly vulnerable to the homocysteine raising effects of low folate status (Table 4).

One possible explanation of the observed relationship between smoking status and homocysteine in females is suggested by epidemiological studies indicating that smoking interferes with estrogen metabolism and that women who smoke are relatively estrogen-deficient [28]. As it has been previously suggested that estrogen decreases plasma homocysteine levels [29], a hormonal mechanism may underly our observations. The precise mechanism by which estrogen could affect homocysteine metabolism is not known. However, it has been proposed that estrogen influences methionine catabolism [30,31], and thus may influence homocysteine levels via this component of the pathway. Another possible mechanism by which estrogen might influence homocysteine concentration has been suggested by Brown et al. [20] who postulated that estrogendependent changes in NOS3 activity influence folate levels [32].

In conclusion, our analyses of data from a cohort of young, reproductive age adults indicate that the predictors of homocysteine levels in males and females are similar, but that the inter-relationships between these predictive factors may differ. These differences indicate that the subgroups of males and females who are at highest risk for hyperhomocysteinemia are distinct. In males, individuals with the MTHFR 677TT genotype appear to be at the highest risk and to be the most vulnerable to factors (e.g. smoking, low folate) that are associated with homocysteine raising effects. In females, smokers (regardless of MTHFR genotype) appear to be at the highest risk, and to be the most vulnerable to other factors (e.g. low folate) that are associated with homocysteine raising effects.

\section{Acknowledgments}

The authors thank Minghua Mei for assistance with data management. Supported by National Institutes of Health Grants AR47663, ES013508 and HD039195, the
Wellcome Trust, and the British Heart Foundation. The authors' work was independent of these funding agencies.

\section{References}

[1] H. Refsum, E. Nurk, A.D. Smith, P.M. Ueland, C.G. Gjesdal, I. Bjelland, A. Tverdal, G.S. Tell, O. Nygard, S.E. Vollset, The Hordaland Homocysteine study: a community-based study of homocysteine, its determinants, and associations with disease, J. Nutr. 136 (2006) 1731S-1740S.

[2] J. Selhub, The many facets of hyperhomocysteinemia: studies from the Framingham cohorts, J. Nutr. 136 (2006) 1726S-1730S.

[3] L.E. Mitchell, N.S. Adzick, J. Melchionne, P.S. Pasquariello, L.N. Sutton, A.S. Whitehead, Spina bifida, Lancet 364 (2004) 1885-1895.

[4] G.M. Shaw, E.J. Lammer, C.R. Wasserman, C.D. O'Malley, M.M. Tolarova, Risks of orofacial clefts in children born to women using multivitamins containing folic acid periconceptionally, Lancet 346 (1995) 393-396.

[5] M. Lucock, Folic acid: nutritional biochemistry, molecular biology, and role in disease processes, Mol. Genet. Metab. 71 (2000) 121-138.

[6] R.P. Steegers-Theunissen, G.H. Boers, F.J. Trijbels, J.D. Finkelstein, H.J. Blom, C.M. Thomas, G.F. Borm, M.G. Wouters, T.K. Eskes, Maternal hyperhomocysteinemia: a risk factor for neural-tube defects? Metabolism 43 (1994) 1475-1480.

[7] T.K. Eskes, R.P. Steegers-Theunissen, Primary prevention of neuraltube defects with folic acid, Eur.J. Obstet. Gynecol. Reprod. Biol. 53 (1994) 147-152.

[8] MRC Vitamin Study Research Group, Prevention of neural tube defects: results of the medical research council vitamin study, Lancet 338 (1991) 131-137.

[9] A. Czeizel, I. Dudas, Prevention of the first occurrence of neural tube defects by periconceptional vitamin supplementation, N. Eng. J. Med. 327 (1992) 1832-1835.

[10] M. Ward, H. McNulty, J. McPartlin, J.J. Strain, D.G. Weir, J.M. Scott, Plasma homocysteine, a risk factor for cardiovascular disease, is lowered by physiological doses of folic acid, QJM 90 (1997) 519524.

[11] J. Schneede, H. Refsum, P.M. Ueland, Biological and environmental determinants of plasma homocysteine, Semin. Thromb. Hemost. 26 (2000) 263-279.

[12] O. Nygard, S.E. Vollset, H. Refsum, I. Stensvold, A. Tverdal, J.E. Nordrehaug, P.M. Ueland, G. Kvale, Total plasma homocysteine and cardiovascular risk profile. The Hordaland Homocysteine Study, JAMA 274 (1995) 1526-1533.

[13] K. Pagan, J. Hou, R.L. Goldenberg, S.P. Cliver, T. Tamura, Effect of smoking on serum concentrations of total homocysteine and B vitamins in mid-pregnancy, Clin. Chim. Acta 306 (2001) 103-109.

[14] A.J. Sobczak, The effects of tobacco smoke on the homocysteine level - a risk factor of atherosclerosis, Addict. Biol. 8 (2003) 147-158.

[15] D.L. Harmon, J.V. Woodside, J.W. Yarnell, D. McMaster, I.S. Young, E.E. McCrum, K.F. Gey, A.S. Whitehead, A.E. Evans, The common 'thermolabile' variant of methylene tetrahydrofolate reductase is a major determinant of mild hyperhomocysteinaemia, QJM 89 (1996) 571-577.

[16] P.F. Jacques, A.G. Bostom, R.R. Williams, R.C. Ellison, J.H. Eckfeldt, I.H. Rosenberg, J. Selhub, R. Rozen, Relation between folate status, a common mutation in methylenetetrahydrofolate reductase, and plasma homocysteine concentrations, Circulation 93 (1996) 7-9.

[17] H. McNulty, L.C. Dowey, J.J. Strain, A. Dunne, M. Ward, A.M. Molloy, L.B. McAnena, J.P. Hughes, M. Hannon-Fletcher, J.M. Scott, Riboflavin lowers homocysteine in individuals homozygous for the MTHFR $677 \mathrm{C} \rightarrow$ T polymorphism, Circulation 113 (2006) 74-80.

[18] A. Chango, G. Potier De Courcy, F. Boisson, J.C. Guilland, F. Barbe, M.O. Perrin, J.P. Christides, K. Rabhi, M. Pfister, P. Galan, S. Hercberg, J.P. Nicolas, 5,10-Methylenetetrahydrofolate reductase common mutations, folate status and plasma homocysteine in healthy 
French adults of the Supplementation en Vitamines et Mineraux Antioxydants (SU.VI.MAX) cohort, Br. J. Nutr. 84 (2000) 891-896.

[19] L.A. Kluijtmans, I.S. Young, C.A. Boreham, L. Murray, D. McMaster, H. McNulty, J.J. Strain, J. McPartlin, J.M. Scott, A.S. Whitehead, Genetic and nutritional factors contributing to hyperhomocysteinemia in young adults, Blood 101 (2003) 2483-2488.

[20] K.S. Brown, L.A. Kluijtmans, I.S. Young, L. Murray, D. McMaster, J.V. Woodside, J.W. Yarnell, C.A. Boreham, H. McNulty, J.J. Strain, J. McPartlin, J.M. Scott, L.E. Mitchell, A.S. Whitehead, The 5,10methylenetetrahydrofolate reductase C677T polymorphism interacts with smoking to increase homocysteine, Atherosclerosis 174 (2004) 315-322.

[21] C. Boreham, J.M. Savage, D. Primrose, G. Cran, J. Strain, Coronary risk factors in schoolchildren, Arch. Dis. Child. 68 (1993) 182-186.

[22] A.M. Gallagher, J.M. Savage, L.J. Murray, G. Davey Smith, I.S. Young, P.J. Robson, C.E. Neville, G. Cran, J.J. Strain, C.A. Boreham, A longitudinal study through adolescence to adulthood: the Young Hearts Project, Northern Ireland, Public Health 116 (2002) 332-340.

[23] C. Boreham, P.J. Robson, A.M. Gallagher, G.W. Cran, J.M. Savage, L.J. Murray, Tracking of physical activity, fitness, body composition and diet from adolescence to young adulthood: the young hearts project, Northern Ireland, Int. J. Behav. Nutr. Phys. Act. 1 (2004) 14.

[24] J.B. Ubbink, W.J. Hayward Vermaak, S. Bissbort, Rapid highperformance liquid chromatographic assay for total homocysteine levels in human serum, J. Chromatogr. 565 (1991) 441-446.

[25] A.M. Molloy, J.M. Scott, Microbiological assay for serum, plasma, and red cell folate using cryopreserved, microtiter plate method, Methods Enzymol. 281 (1997) 43-53.
[26] S.A. Miller, D.D. Dykes, H.F. Polesky, A simple salting out procedure for extracting DNA from human nucleated cells, Nucleic Acids Res. 16 (1988) 1215.

[27] Introduction of linear regression analysis. Chapter 9. Variable Selection and Model Building, Montgomery DC, Peck EA and Vining GG. John Wiley and Sons, Inc. New Jersey, 2006.

[28] J.A. Baron, C. LaVecchia, F. Levi, The antiestrogenic effect of cigarette smoking in women, Am. J. Obstet. Gynecol. 162 (1990) 502 514.

[29] M.S. Morris, P.F. Jacques, J. Selhub, I.H. Rosenberg, Total homocysteine and estrogen status indicators in the Third National Health and Nutrition Examination Survey, Am. J. Epidemiol. 152 (2000) $140-148$.

[30] G.H. Boers, A.G. Smals, F.J. Trijbels, A.I. Leermakers, P.W. Kloppenborg, Unique efficiency of methionine metabolism in premenopausal women may protect against vascular disease in the reproductive years, J. Clin. Invest. 72 (1983) 1971-1976.

[31] H.J. Blom, G.H. Boers, J.P. van den Elzen, J.J. van Roessel, J.M. Trijbels, A. Tangerman, Differences between premenopausal women and young men in the transamination pathway of methionine catabolism, and the protection against vascular disease, Eur. J. Clin. Invest. 18 (1988) 633-638.

[32] K.S. Brown, L.A. Kluijtmans, I.S. Young, J. Woodside, J.W. Yarnell, D. McMaster, L. Murray, A.E. Evans, C.A. Boreham, H. McNulty, J.J. Strain, L.E. Mitchell, A.S. Whitehead, Genetic evidence that nitric oxide modulates homocysteine: the NOS3 894TT genotype is a risk factor for hyperhomocystenemia, Arterioscler. Thromb. Vasc. Biol. 23 (2003) 1014-1020. 